\title{
Biodiversity of yeasts isolated during spontaneous fermentation of cool climate grape musts
}

\author{
Monika Cioch-Skoneczny ${ }^{1}\left[\right.$ D $\cdot$ Paweł Satora ${ }^{1} \cdot$ Szymon Skoneczny ${ }^{2} \cdot$ Magdalena Skotniczny $^{1}$
}

Received: 15 April 2020 / Revised: 31 July 2020 / Accepted: 5 August 2020 / Published online: 11 August 2020

(C) The Author(s) 2020

\begin{abstract}
Biodiversity of native yeasts, especially in winemaking, has hidden potential. In order to use the value of non-Saccharomyces strains in wine production and to minimise the possibility of its deterioration, it is necessary to thoroughly study the yeast cultures present on grape fruits and in grape must, as well as their metabolic properties. The aim of the study was to characterise the yeast microbiota found during spontaneous fermentation of grape musts obtained from grape varieties 'Rondo', 'Regent' and 'Johanniter'. Grapes from two vineyards (Srebrna Góra and Zadora) located in southern Poland were used for the research. Succession of subsequent groups of yeasts was observed during the process. Metschnikowia pulcherrima yeasts were identified both at the beginning and the end of the process. Hanseniaspora uvarum, Wickerhamomyces onychis and Torulaspora delbrueckii strains were also identified during the fermentation. Torulaspora delbrueckii and Wickerhamomyces onychis strains were identified only in grape musts obtained from grapes of the Zadora vineyard. These strains may be characteristic of this vineyard and shape the identity of wines formed in it. Our research has provided specific knowledge on the biodiversity of yeast cultures on grapes and during their spontaneous fermentation. The research results presented indicate the possibility of using native strains for fermentation of grape musts, allowing to obtain a product with favourable chemical composition and sensory profile.
\end{abstract}

Keywords Non-Saccharomyces · Spontaneous fermentation · Cool climate · RAPD-PCR · 5.8S-ITS rRNA gene

\section{Introduction}

Grape must is a rich environment for various yeast species. Knowledge of the kinetics of their growth and metabolism is fundamental for understanding the influence of these microorganisms on the quality of wine. Fermentation process is related to several mechanisms, including metabolism of sugars and nitrogen compounds contained in grape must, enzymatic hydrolysis of grape components, yeast cell autolysis and bioadsorption of individual must components. All

Communicated by Erko Stackebrandt.

Monika Cioch-Skoneczny monika.cioch@urk.edu.pl

1 Department of Fermentation Technology and Microbiology, University of Agriculture in Krakow, ul. Balicka 122, 30-149, Krakow, Poland

2 Department of Chemical and Process Engineering, Faculty of Chemical Engineering and Technology, Cracow University of Technology, Warszawska 24, 31-155 Krakow, Poland these factors determine the formation of a large number of compounds from the group of organic acids, higher alcohols, aldehydes or ketones, esters, glycerol responsible for the taste and smell of wine (Swiegers et al. 2005).

In the early stages of fermentation, the amount of nonSaccharomcyes yeast ranges from $10^{3}-10^{5}$ to $10^{6}-10^{7} \mathrm{CFU} /$ mL (Hierro et al. 2006; Zott et al. 2008). Studies show high biodiversity of yeast microorganisms during the first 24-72 $\mathrm{h}$ of the process (Zott et al. 2008; Ocón et al. 2010). Factors such as mechanical damage of berries, agronomic practices and terroir (soil type, average annual temperature, rainfall) directly affect the biota of yeasts present on the surface of grapes (Barata et al. 2012; Díaz et al. 2013; DrumondeNeves et al. 2016; Grangeteau et al. 2017).

Quantitative and qualitative characteristics of yeasts present on the grapes surface, must and wine were determined in numerous studies. It was found that the complexity of yeast microbiota during spontaneous grape must fermentation has a significant influence on the organoleptic and sensory properties of wine (Jolly et al. 2014; Padilla et al. 2016; Varela and Borneman 2017). Species from the genus 
Hanseniaspora, Candida, Pichia, Zygosaccharomyces and Kluyveromyces most desirably determine the diversity and complexity of the taste of wine (Romano et al. 2003; Jolly et al. 2014).

According to the decision of European Council of 20 December 2005, Poland was entered into so-called A zone of wine growing (the coldest one), referred to as 'cool climate' zone. Despite increasing temperatures caused by climate changes, conditions for growing vines in Poland are much less propitious than in traditional wine regions. Due to climatic and soil conditions, the obtained grapes are characterised by a lower content of sugars (usually 17-23\%) and thus a low level of alcohol as well as higher acidity (Lisek 2011). However, this has its advantages in the form of a better balance between the content of sugar, acid and the $\mathrm{pH}$ value, as well as better cumulation of some aromatic compounds. Thanks to this, the cool climate wines can achieve very good quality. Higher acidity gives a sense of freshness, especially in the case of white wines (Sluys 2006). The grape varieties currently grown in Poland are characteristic of the cool climate region. Detailed research on the microbiota of grapes and grape must allow the identification of yeast strains characteristic to a specific terroir and defining the 'identity' of a regional wine.

The aim of the study was to characterise the yeast microbiota found during spontaneous fermentation of grape musts obtained from cool climate grape varieties 'Rondo', 'Regent' and 'Johanniter'.

\section{Materials and methods}

\section{Grapes and spontaneous fermentation of musts}

Grapes of two red grape vine varieties ('Rondo', 'Regent') and one white grape variety ('Johanniter') from two vineyards located in southern Poland (Srebrna Góra-50 $2^{\prime} \mathrm{N}$, $19^{\circ} 50^{\prime} \mathrm{E}$, and Zadora-49 $53^{\circ} \mathrm{N}, 21^{\circ} 52^{\prime} \mathrm{E}$ ) during two consecutive vintages (2013 and 2014) were taken in account of the study (Table 1).

Ten bunches of mature grapes were gathered from several grape vines within a sub-area of each vineyard (100 $\left.\mathrm{m}^{2}\right)$. Then, berries were randomly selected $(500 \mathrm{~g})$, placed in sterile 500-mL flasks and pressed until juice has covered the fruits. The flasks were closed with airlocks filled with glycerine. Fermentation was carried out for 28 days at a temperature of $20^{\circ} \mathrm{C}$ (each in triplicate).

\section{Physicochemical characteristics of grape musts}

The analyses of $\mathrm{pH}$, total acidity and sugar content were performed in accordance with the methodology described by Cioch-Skoneczny et al. (2018).
Table 1 Grape varieties used in the study and harvest dates of grapes

\begin{tabular}{lll}
\hline Grape variety & \multicolumn{2}{l}{ Vineyard } \\
\cline { 2 - 3 } & Srebrna Góra & Zadora \\
\hline Rondo & - & 25.09 .2013 \\
& & 28.09 .2014 \\
Regent & - & 25.09 .2013 \\
& & 28.09 .2014 \\
Johanniter & 8.10 .2013 & 25.09 .2013 \\
& 4.10 .2014 & 28.09 .2014 \\
\hline
\end{tabular}

\section{Yeasts enumeration and isolation, DNA extraction and RAPD-PCR analysis, amplification of the 5.8S-ITS rRNA gene region, PCR-RFLP analysis}

The analyses were performed in accordance with the methodology described by Cioch-Skoneczny et al. (CiochSkoneczny et al. 2018).

\subsection{S-ITS rRNA gene region sequencing}

Amplified product of the rRNA gene was purified using Clean up AX (A\&A Biotechnology, Poland) according to the manufacturer's instruction and submitted for sequencing to Macrogen Inc. (Netherlands). Species identification was achieved by comparing processed sequences with available in the GenBank database using the basic local alignment search tool (BLAST) at the https://www.ncbi.nlm.nih.gov/ BLAST/. Percent homology scores were generated to identify yeast isolates. Sequences were deposited in the GenBank NCBI database with the accession numbers: MG971248 (Torulaspora delbrueckii), MG971245, MG971262 and MG971256 (Metschnikowia pulcherrima), MG971254 and MG971266 (Hanseniaspora uvarum), MG971267 (Candida railenensis), MH020215 (Saccharomyces cerevisiae) and MG971246 (Wickerhamomyces onychis).

\section{Results and discussion}

\section{Kinetics of yeast population}

The number of yeasts during spontaneous fermentation of grape musts remained at a similar level for all analysed grape varieties in 2014. In 2013, there were a smaller number of yeasts, in average by $4-5$ logarithmic rows (Figs. 1 and 2). It could be caused by a small amount of food resources present in the fermenting medium in 2013, which probably limited the growth of microorganisms. Late spring frosts and early in the fruit ripening period, cooling and rain during 


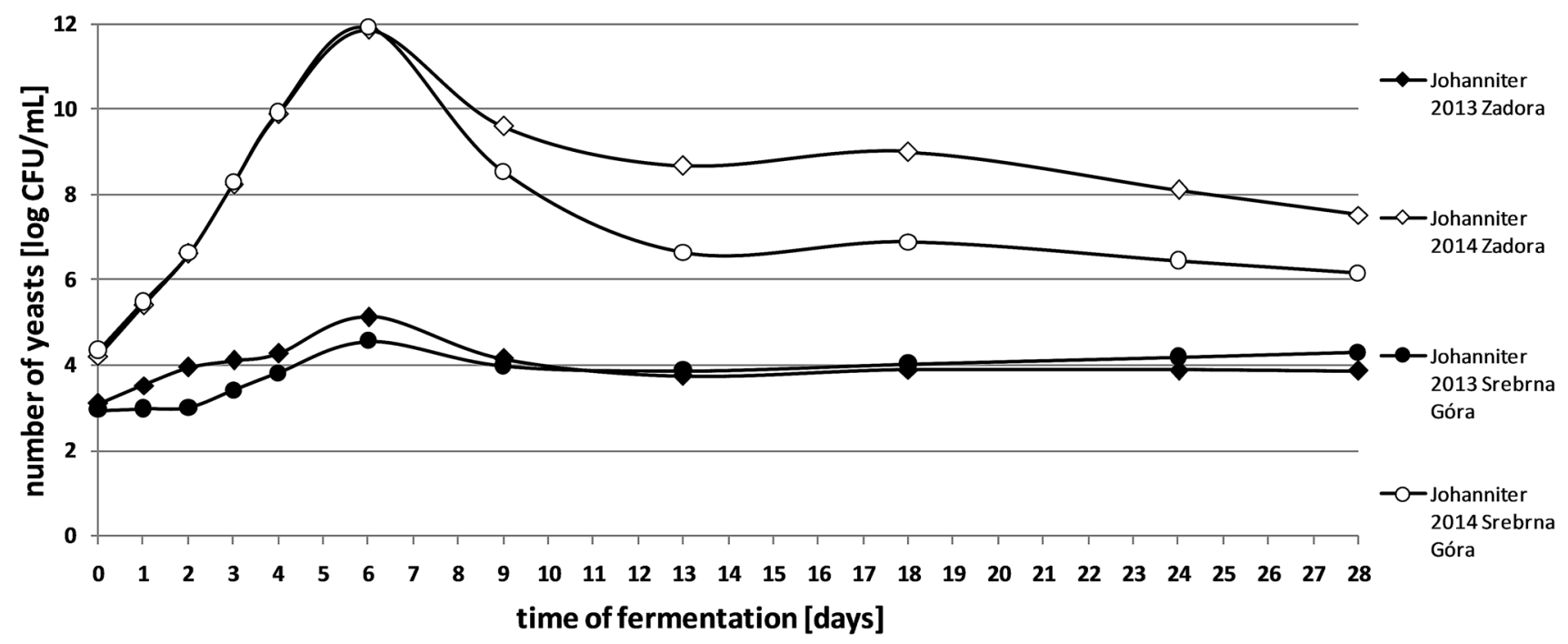

Fig. 1 Quantitative microbiota of yeasts in spontaneously fermented grape musts obtained from Johanniter variety

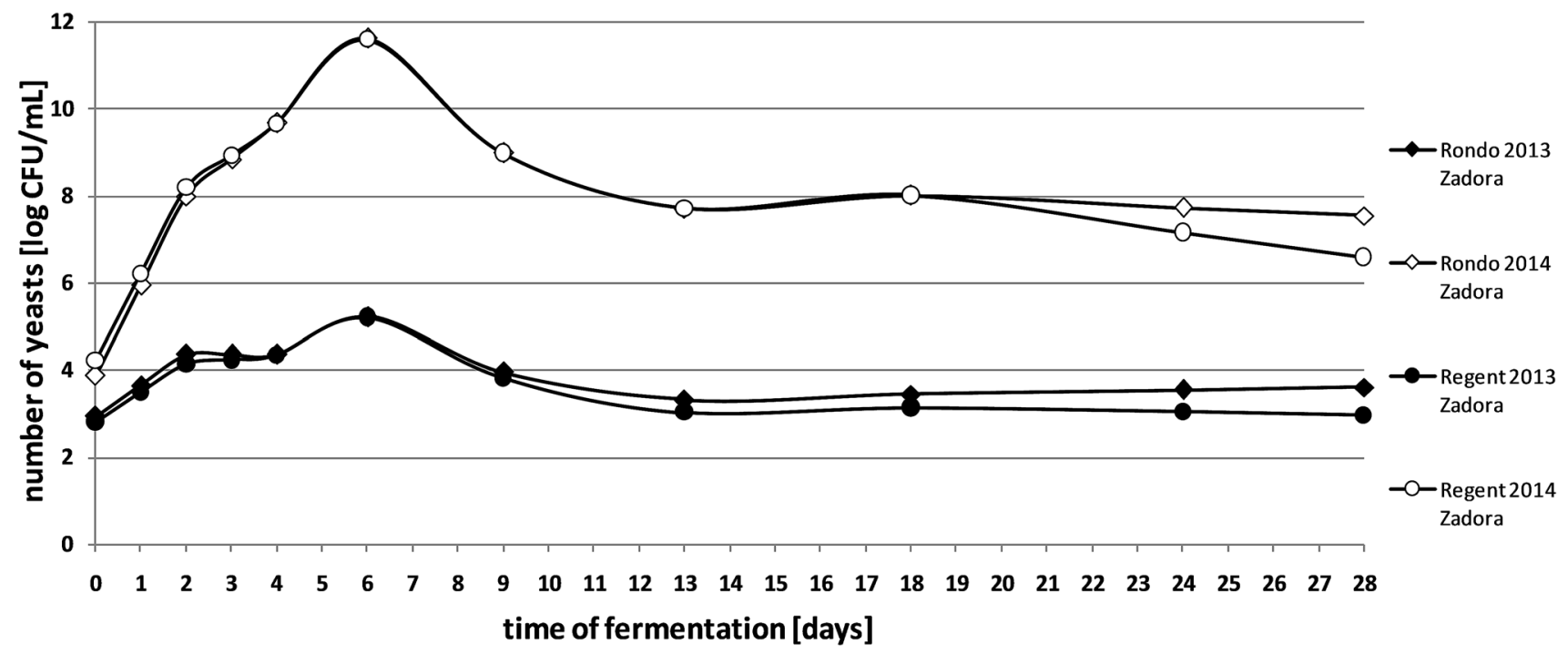

Fig. 2 Quantitative microbiota of yeasts in spontaneously fermented grape musts obtained from Rondo and Regent varieties

flowering of the vine and additionally, the excess of rainfall in the summer season certainly influenced the quality of the grapes and the quantitative microbiota composition. According to literature data, the number of yeasts in fresh grape must varies in a wide range from $10^{3}$ to $10^{7} \mathrm{CFU} / \mathrm{mL}$ (Hierro et al. 2006; Zott et al. 2008). This differentiation depends mainly on the degree of maturity, chemical composition and mechanical damage of fruits. The content of sugar and water in grapes is also significant, as well as $\mathrm{pH}$ value of must (Swiegers et al. 2005).

In 2014, in the first days of fermentation, a rapid increase in the yeast population in all analysed settings was observed. In 2013, this increase was slight (Figs. 1 and 2). In the initial phase of spontaneous fermentation mainly aerobic strains are developing, not very resistant to elevated alcohol concentration (Hornsey 2007).

A maximum of cells number in the grape musts was noted from the 6th to the 13th day of the process. The fast growth of yeasts at this stage of fermentation is confirmed by other studies (Romano et al. 2003).

After reaching the maximum of cells in grape musts, the number of microorganisms gradually decreased. This tendency continued until the end of the fermentation process in the batches obtained from the fruits from both vineyards (2014) (Figs. 1 and 2). Most likely, it was the result of the dieback of yeast species sensitive to the increasing 
concentration of alcohol, as well as the depletion of nutrients contained in the must and the accumulation of metabolites having an inhibitory effect on the growth of microorganisms. Literature data indicate that components produced during fermentation, such as fatty acids and ethanol, may also act as inhibitors that slow cell uptake of nitrogen. In addition, changing conditions, including oxygenation and clarification of must, have an undesirable effect on yeast growth and kinetics of the whole process (Ribéreau-Gayon et al. 2006). In the 2013 season, a slight increase in the number of microorganisms was noted at the end of spontaneous fermentation. At this stage of the process, strains of the genus Saccharomyces, resistant to higher concentrations of alcohol, predominate (Jolly et al. 2014).

Apart from determining the total yeast content, cultures on the WL medium allowed us to study the number of Kloeckera/Hanseniaspora sp. yeasts during spontaneous fermentation. Their content in fresh juices from 'Rondo' variety in 2014 season was $3.23 \times 10^{3} \mathrm{CFU} / \mathrm{mL}$. A comparable number of microorganisms was observed in fresh juices obtained from the 'Regent' and 'Johanniter' varieties (Srebrna Góra vineyard). These microorganisms were not recorded in fresh musts of the 'Johanniter' variety from Zadora vineyard. A similar dependence was found in 2013 season for all of analysed samples (Figs. 3 and 4). Studies show that some species belonging to the genus Kloeckera/Hanseniaspora show the ability to grow only under anaerobic conditions (Van de Water and Napa 2009). This may be the reason of missing them in the early days of fermentation in 2013 season.

The maximum yeast population in spontaneously fermented grape musts was recorded from the 5th to the 8th day of the process. While Kloeckera/Hanseniaspora species are the dominant microbiota in the first days of spontaneous fermentation, Saccharomyces strains are present in virtually undetectable quantities (Romano et al. 2003). In 2013, at this stage of fermentation, almost all detected yeasts belonged to the genus Kloeckera/Hanseniaspora (Figs. 1, 2, 3 and 4). Certainly, they did not actually represent all yeast present in the must, but their large numbers made the probability of isolation of these microorganisms high. This group of yeasts constituted even up to $95 \%$ of all microorganisms present in the batches. Literature results confirm such a high share of Kloeckera/Hanseniaspora yeast in grape musts at early stages of fermentation, which may amount to $99 \%$ of the entire microbiota (Ribéreau-Gayon et al. 2006).

Afterwards, the number of Kloeckera/Hanseniaspora cells in the analysed musts began to gradually decreased. From the 24th day of spontaneous fermentation, the presence of these cultures in the batches was not recorded (Figs. 3 and 4). Literature data report that some of this species can survive up to the last stages of the fermentation. In addition, these yeasts show tolerance to high concentrations of $\mathrm{SO}_{2}$ and low temperatures (Van de Water and Napa 2009). Selective use of fructose by some Kloeckera/Hanseniaspora species improves saccharide utilisation by Saccharomyces yeast, by reducing the risk of occurrence of the residual sugars after fermentation (Ciani and Fatichenti 1999).

\section{Physicochemical characteristics of grape musts}

Depending on the variety, grape musts were characterised by a different acidity and sugar content (Table 2). Concentration of total sugars was quite similar within the varieties and ranged from $164.17 \mathrm{~g} / \mathrm{L}$ (in 'Rondo' musts from Zadora 2014) to $223.80 \mathrm{~g} / \mathrm{L}$ (in 'Johanniter' musts

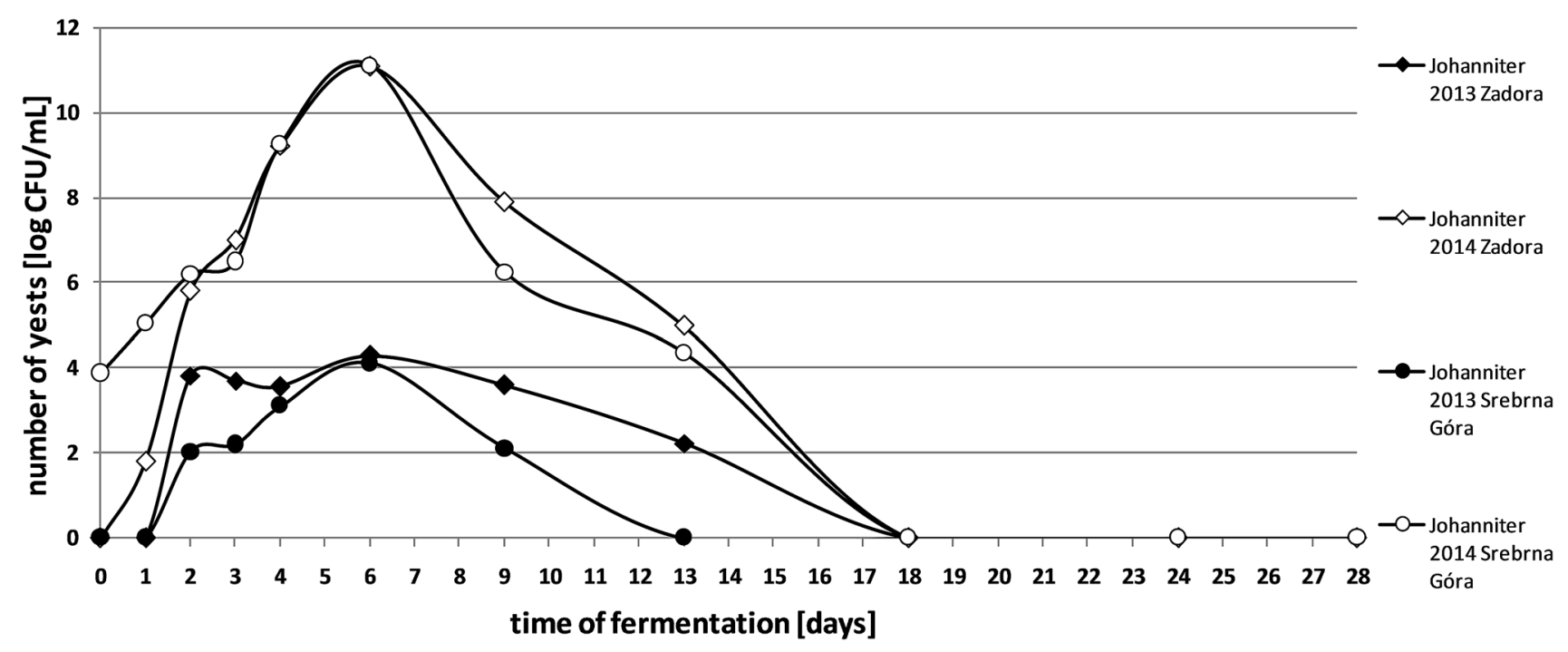

Fig. 3 Changes in the number of Kloeckera/Hanseniaspora yeasts in spontaneously fermented grape musts obtained from Johanniter variety 


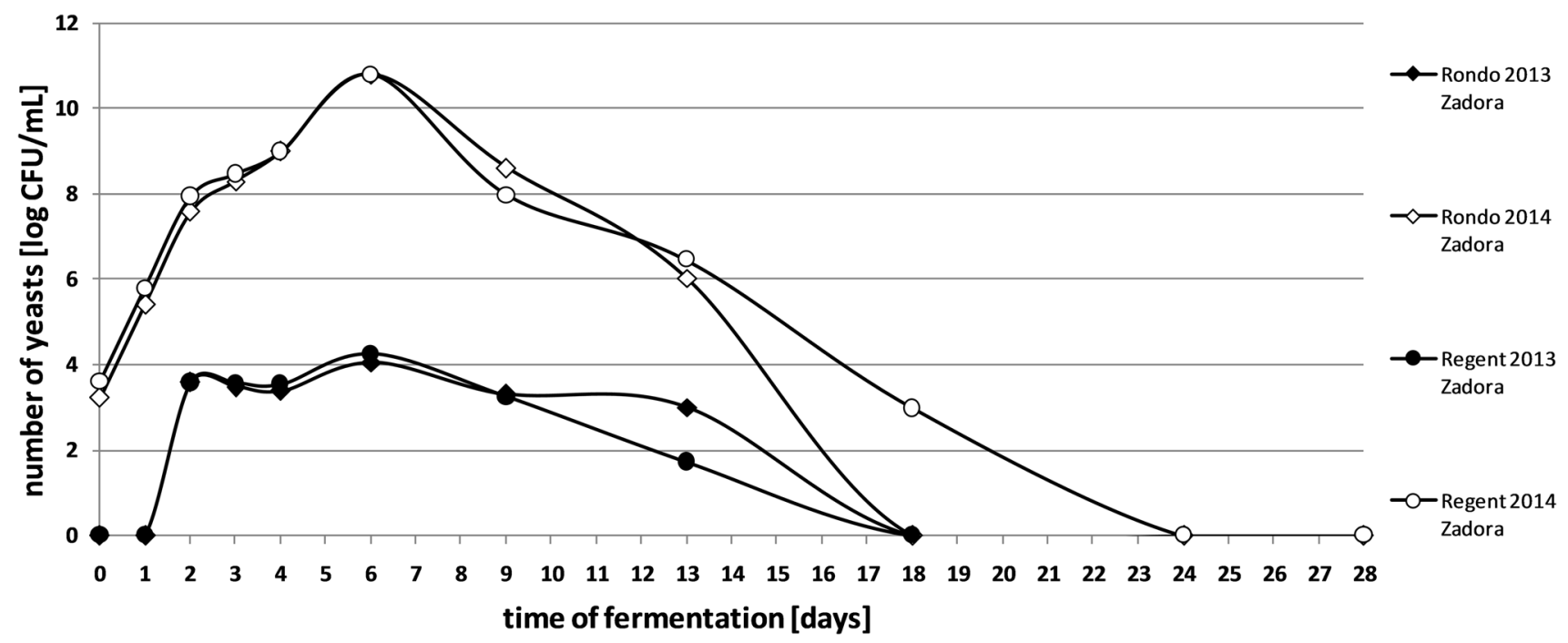

Fig. 4 Changes in the number of Kloeckera/Hanseniaspora yeasts in spontaneously fermented grape musts obtained from Rondo and Regent varieties

Table 2 Characteristics of grape musts obtained from the Rondo, Regent and Johanniter grape varieties

\begin{tabular}{|c|c|c|c|c|c|}
\hline Season & Vineyard & $\begin{array}{l}\text { Grape } \\
\text { variety }\end{array}$ & $\mathrm{pH}$ & $\begin{array}{l}\text { Total acid- } \\
\text { ity } \\
{[\mathrm{g} / \mathrm{L}]^{\mathrm{a}}}\end{array}$ & $\begin{array}{l}\text { Sugars } \\
{[\mathrm{g} / \mathrm{L}]}\end{array}$ \\
\hline 2013 & $\begin{array}{c}\text { Srebrna } \\
\text { Góra }\end{array}$ & Johanniter & $\begin{array}{l}3.12 \mathrm{c} \\
( \pm 0.00)\end{array}$ & $\begin{array}{l}8.40 \mathrm{~g} \\
( \pm 0.00)\end{array}$ & $\begin{array}{l}223.80 \mathrm{c} \\
( \pm 5.51)\end{array}$ \\
\hline 2014 & $\begin{array}{c}\text { Srebrna } \\
\text { Góra }\end{array}$ & & $\begin{array}{l}3.19 \mathrm{a} \\
( \pm 0.01)\end{array}$ & $\begin{array}{l}8.03 \mathrm{~d} \\
( \pm 0.00)\end{array}$ & $\begin{array}{r}204.17 \mathrm{a} \\
( \pm 8.04)\end{array}$ \\
\hline 2013 & Zadora & & $\begin{array}{l}3.06 \mathrm{~b} \\
( \pm 0.01)\end{array}$ & $\begin{array}{l}8.20 \mathrm{f} \\
( \pm 0.00)\end{array}$ & $\begin{array}{l}214.00 \mathrm{ac} \\
( \pm 3.12)\end{array}$ \\
\hline 2014 & Zadora & & $\begin{array}{l}3.20 \mathrm{a} \\
( \pm 0.02)\end{array}$ & $\begin{array}{l}11.01 \mathrm{a} \\
( \pm 0.00)\end{array}$ & $\begin{array}{l}166.67 b \\
( \pm 2.89)\end{array}$ \\
\hline 2013 & Zadora & Rondo & $\begin{array}{l}3.06 \mathrm{~b} \\
( \pm 0.01)\end{array}$ & $\begin{array}{l}8.13 \mathrm{e} \\
( \pm 0.02)\end{array}$ & $\begin{array}{l}201.50 \mathrm{a} \\
( \pm 5.63)\end{array}$ \\
\hline 2014 & Zadora & & $\begin{array}{l}3.11 \mathrm{c} \\
( \pm 0.01)\end{array}$ & $\begin{array}{l}9.89 \mathrm{~h} \\
( \pm 0.00)\end{array}$ & $\begin{array}{l}164.17 b \\
( \pm 3.82)\end{array}$ \\
\hline 2013 & Zadora & Regent & $\begin{array}{l}3.21 \mathrm{a} \\
( \pm 0.02)\end{array}$ & $\begin{array}{l}6.72 \mathrm{~b} \\
( \pm 0.01)\end{array}$ & $\begin{array}{r}205.83 a \\
( \pm 6.29)\end{array}$ \\
\hline 2014 & Zadora & & $\begin{array}{l}3.31 \mathrm{~d} \\
( \pm 0.07)\end{array}$ & $\begin{array}{l}7.28 \mathrm{c} \\
( \pm 0.01)\end{array}$ & $\begin{array}{l}165.00 \mathrm{~b} \\
( \pm 8.66)\end{array}$ \\
\hline
\end{tabular}

The results marked with the same letters do not differ significantly $(p>0.05)$

${ }^{\mathrm{a}}$ Expressed in $\mathrm{g} / \mathrm{L}$ of malic acid

from Srebrna Góra 2013). In 2014 the concentrations of total sugars in grapes were lower than in the 2013 season (Table 2). 'Johanniter' must (Zadora 2014) characterised also relatively high total acidity $(11.01 \mathrm{~g} / \mathrm{L})$.

\section{Yeasts identification}

In total, 162 (in 2013) and 78 (in 2014) pure yeast cultures were isolated from various stages of fermented musts three varieties of grapes.

Isolates were typed by RAPD-PCR in order to characterise the identical biotypes and to reduce the number of samples taken for further analysis. All isolates were classified into groups characterised by distinct electrophoretic patterns.

Representatives of each groups of RAPD patterns were analysed by 5.8S-ITS PCR-RFLP. Ultimately, representatives of each groups of RFLP patterns were identified by 5.8S-ITS rRNA gene region sequencing.

In 2013 and 2014 seven different yeast species were distinguished. According to the sequencing results, the most identified strains belonged to the species Metschnikowia pulcherrima, Wickerhamomyces onychis, Torulaspora delbrueckii, Candida railenensis, Saccharomyces cerevisiae and Hanseniaspora uvarum (Table 3).

Tables 4, 5, 6 and 7 present the percentage distribution of yeast strains isolated from different stages of spontaneous fermentation of grape musts obtained from 'Rondo', 'Regent' and 'Johanniter' varieties in two consecutive years. The cultures of $M$. pulcherrima dominated. They were identified at each stage of spontaneous fermentation of grape musts. W. onychis and T. delbrueckii species were isolated from the Zadora vineyard from fermented 'Johanniter' and 'Regent' musts.

Most of the identified microorganisms belonged to the genus Kloeckera/Hanseniaspora (described above) and M. pulcherrima species. These yeasts occurred frequently 
Table 3 Identified yeast species on the basis of their lengths of restriction fragments of the 5.8S-ITS rRNA gene region and the highest 5.8S-ITS rRNA similarity score

\begin{tabular}{|c|c|c|c|c|c|}
\hline \multirow[t]{2}{*}{ 5.8S-ITS [bp] } & \multicolumn{3}{|c|}{ Restriction fragments [bp] } & \multirow[t]{2}{*}{ Species identification (\% identity)* } & \multirow[t]{2}{*}{ Accession no } \\
\hline & Hinf I & Hae III & Cfo $I$ & & \\
\hline 650 & $350+180+150$ & 650 & 300 & Candida railenensis $(99 \%)^{1}$ & MG971267 \\
\hline 750 & $350+190$ & $390+290+180+120$ & $320+200+170+100$ & Hanseniaspora uvarum (98\%) & MG971254 \\
\hline 750 & 320 & $380+220$ & 750 & Hanseniaspora uvarum (98\%) & MG971266 \\
\hline 390 & 200 & 300 & $210+100$ & Metschnikowia pulcherrima (99\%) & MG971245 \\
\hline 390 & $350+200$ & $300+200$ & $200+180$ & Metschnikowia pulcherrima (99\%) & MG971256 \\
\hline 390 & 200 & $280+180$ & $210+180+100$ & Metschnikowia pulcherrima (98\%) & MG971262 \\
\hline 880 & 400 & $350+250+200+150$ & 350 & Saccharomyces cerevisiae $(98 \%)^{2}$ & МH020215 \\
\hline 800 & $400+200$ & 800 & $350+250+150$ & Torulaspora delbrueckii (98\%) & MG971248 \\
\hline $600 / 650$ & $350+200$ & $650+500+350$ & $450+350+180$ & Wickerhamomyces onychis $(98 \%)^{3}$ & MG971246 \\
\hline
\end{tabular}

*According to BlastN search of 5.8S-ITS rRNA gene sequences in NCBI database

${ }^{1}$ Isolated from spontaneously fermented musts of Rondo and Regent grape varieties (Spotkaniówka and Srebrna Góra vineyard)

${ }^{2}$ Isolated from spontaneously fermented musts of Rondo and Bianca grape varieties (Spotkaniówka vineyard), Hibernal variety (Spotkaniówka and Srebrna Góra vineyard) and Seyval Blanc variety (Srebrna Góra vineyard)

${ }^{3}$ Isolated from spontaneously fermented musts of Seyval Blanc grape variety (Zalipie vineyard)

during the entire fermentation process in settings from both vineyards (Tables 4, 5, 6 and 7). However, the M. pulcherrima strain (MG971245) was not registered in grape musts and wines obtained from the white grape 'Johanniter' variety. Bisson and Joseph (Bisson and Joseph 2009) showed a high participation of strains, among others from Metschnikowia genus, on the surface of ripe grapes. Literature data indicate a decrease in the number of these cultures in grape must after 100-130 $\mathrm{h}$ of spontaneous fermentation and their absence after 10 days of the process (Cocolin et al. 2000). In turn tests carried out by Díaz et al. (2013) have proved the occurrence of $M$. pulcherrima strains in fermenting grape musts at least 5 days longer. Medina et al. (2012) have reported that Hanseniaspora viniae and M. pulcherrima strains can use enough nutrients, contributing to slow down fermentation.

Candida railenensis strain was identified in all fermented grape musts. It was not detected in the final stage of spontaneous fermentation, which is confirmed by our earlier research (Cioch-Skoneczny et al. 2018). These species dominate in the early stages of the process (Jolly et al. 2006; Bagheri et al. 2015).

Wickerhamomyces onychis strain was identified in fermented grape musts obtained from the 'Regent' and 'Johanniter' varieties (Zadora vineyard) (Tables 4 and 7). There is little information on the occurrence of this species in grape musts. However, it is known that strains belonging to the genus Wickerhamomyces may persist in must until the end of the fermentation process (Díaz et al. 2013). Some of them tolerate up to $12.5 \%$ (v/v) of ethanol. They are also able to produce killer toxins (Walker 2011; Sabel et al. 2014), which allowing them to compete with other yeasts in the same environment. However, in fermenting musts, their growth is limited due to the lack of oxygen (Walker 2011). Numerous studies have proved the occurrence of $W$. anomalus strains in fermented grape musts (de Ponzzes-Gomes et al. 2014; Bagheri et al. 2015). These yeasts were identified in musts obtained from Polish white grape variety-'Hibernal' (Cioch-Skoneczny et al. 2019). The presence of these strains in cultures mixed with $S$. cerevisiae strains contributes to the improvement of the aroma of wines (Izquierdo Cañas et al. 2014).

In recent years, the use of non-Saccharomyces yeast for the production of industrial wine has been considered (Romano et al. 2003; Suárez-Lepe and Morata 2012). Studies show that some species, such as M. pulcherrima, Torulaspora delbrueckii, Hanseniaspora uvarum, Rhodoturula mucillaginosa, Pichia kluyveri or Candida spp. used in monocultures or cultures mixed with $S$. cerevisiae, can improve the taste characteristics of wine (Gobbi et al. 2013; Belda et al. 2015). T. delbrueckii species shows special properties. Controlled inoculation of this yeast is recommended to improve the complexity and enhancement of wine traits (Jolly et al. 2006; Azzolini et al. 2012). Their presence contributes to the increase of glycerol in wine (Contreras et al. 2014) and mannoproteins (Belda et al. 2015), as well as to the reduction of alcohol content (Contreras et al. 2014). It has been proven that mixed with $S$. cerevisiae strains, they can contribute to the reduction of volatile acidity, acetoin and acetaldehyde levels (Velázquez et al. 2015), leading to growth content of 2-phenylethanol, terpinenol and lactones in wine (Azzolini et al. 2012; Velázquez et al. 2015). T. delbrueckii yeast was not detected in spontaneously fermented grape musts 

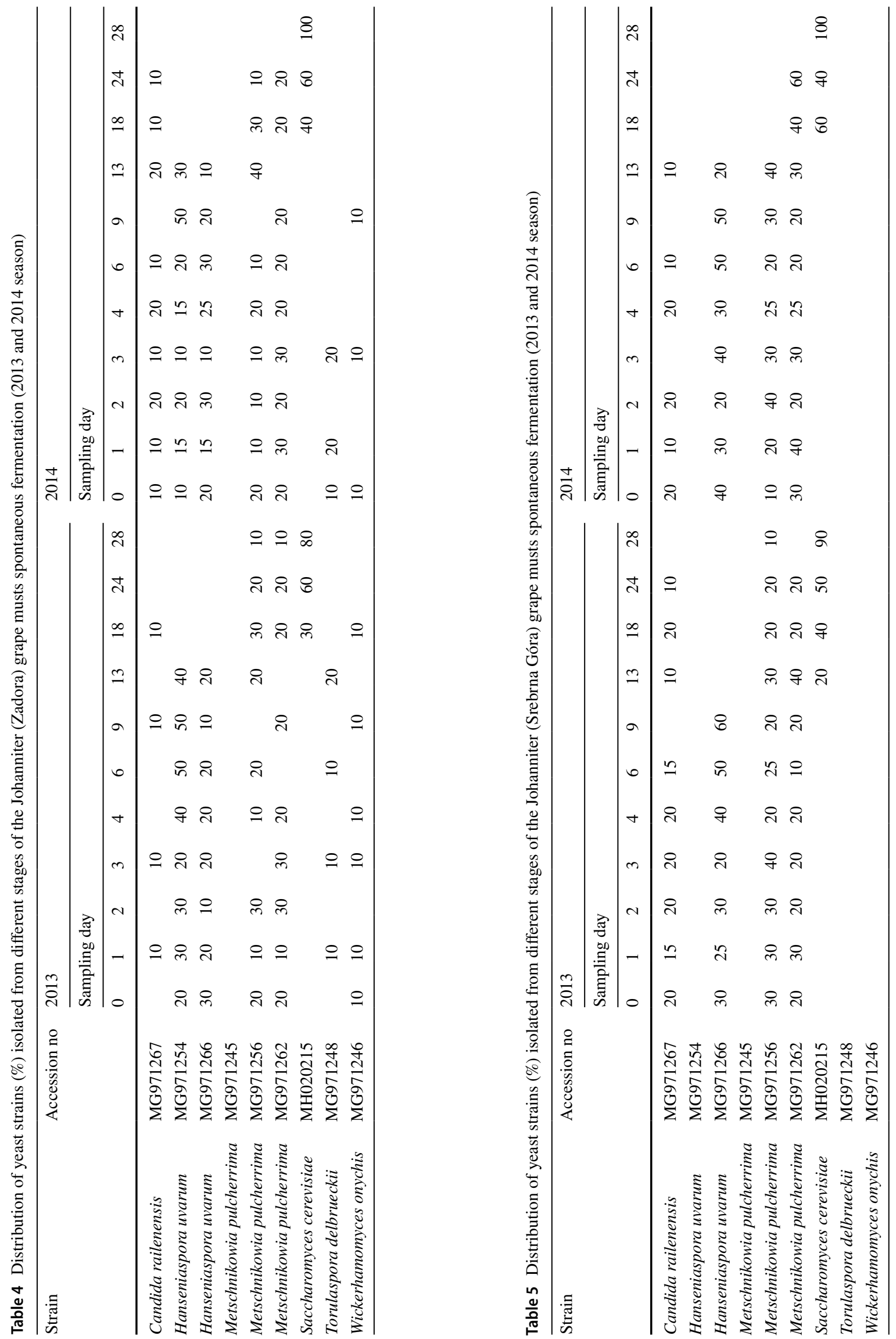


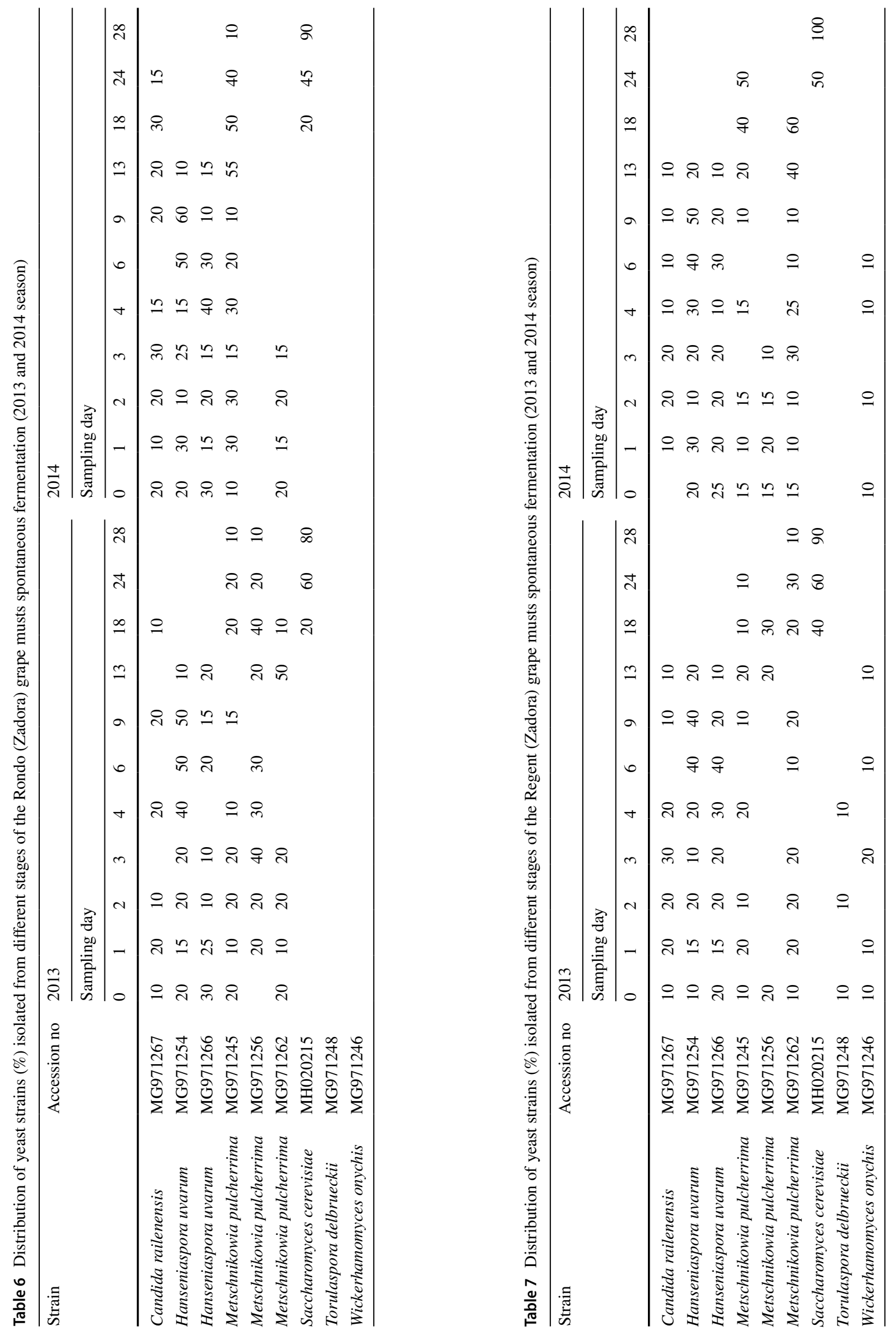


of 'Johanniter' variety obtained from the Srebrna Góra vineyard (Table 5).

Saccharomyces cerevisiae yeast are one of the dominant cultures present during spontaneous must fermentation, responsible for the chemical and sensory properties of wine (Romano et al. 2003; Camarasa et al. 2011). Numerous studies based on the analysis of DNA polymorphism indicate a large genetic diversity of this species (Capece et al. 2013). Despite the appearance of a significant number of different strains of $S$. cerevisiae at the beginning of fermentation, only a few (from one to three) predominate in the final stage (Capece et al. 2016). Research conducted by Knight et al. (2015) concerning the biogeographic characterisation of $S$. cerevisiae wine yeasts revealed the presence of a regional population with a specific genotype, but without differentiation within the region. These experiments suggest that specific, native strains may be associated with terroir and determine the typical nature of wines (Van Leeuwen and Seguin 2006; Capece et al. 2016). In the analysed grape must, one strain of S. cerevisiae (Tables 4, 5, 6 and 7) was detected, which dominated at the end of the spontaneous fermentation step. On the last day of the process, the number of identified isolates reached nearly $100 \%$.

\section{Conclusions}

Grape musts obtained from fruits of the red grape varieties 'Rondo', 'Regent' and white variety 'Johanniter' proved to be a very good environment for yeast growth. In comparison with 2014, the 2013 season was characterised by a smaller content of microorganisms in fresh grape juice, which resulted in their quantity during spontaneous fermentation. The highest number of microorganisms constituted Hanseniaspora strains, which, after the 13th day of fermentation, were replaced by Saccharomyces cultures. Torulaspora delbrueckii and Wickerhamomyces onychis strains were identified only in grape musts obtained from fruits from the Zadora vineyard. These strains may be characteristic of this vineyard and shape the identity of wines formed in it.

\begin{abstract}
Author contributions MC-S and PS helped in conceptualisation; methodology; validation; supervision; and funding acquisition; SS helped in software; MC-S and MS contributed to formal analysis and investigation; MC-S helped in resources; data curation; writing - original draft preparation; and project administration; MC-S, SS and PS wrotereview and editing; MC-S and SS helped in visualisation. All authors have read and agreed to the published version of the manuscript.
\end{abstract}

\section{Compliance with ethical standards}

Conflicts of interest The authors declare no conflict of interest.
Human and animal rights statement This article does not contain any studies with human participants or animals performed by any of the authors.

Open Access This article is licensed under a Creative Commons Attribution 4.0 International License, which permits use, sharing, adaptation, distribution and reproduction in any medium or format, as long as you give appropriate credit to the original author(s) and the source, provide a link to the Creative Commons licence, and indicate if changes were made. The images or other third party material in this article are included in the article's Creative Commons licence, unless indicated otherwise in a credit line to the material. If material is not included in the article's Creative Commons licence and your intended use is not permitted by statutory regulation or exceeds the permitted use, you will need to obtain permission directly from the copyright holder. To view a copy of this licence, visit http://creativecommons.org/licenses/by/4.0/.

\section{References}

Azzolini M, Fedrizzi B, Tosi E et al (2012) Effects of Torulaspora delbrueckii and Saccharomyces cerevisiae mixed cultures on fermentation and aroma of Amarone wine. Eur Food Res Technol 235:303-313. https://doi.org/10.1007/s00217-012-1762-3

Bagheri B, Bauer FF, Setati ME (2015) The diversity and dynamics of indigenous yeast communities in grape must from vineyards employing different agronomic practices and their influence on wine fermentation. S Afr J Enol Vitic 36:243-251. https://doi. org/10.21548/36-2-957

Barata A, Malfeito-Ferreira M, Loureiro V (2012) The microbial ecology of wine grape berries. Int J Food Microbiol 153:243-259. https://doi.org/10.1016/J.IJFOODMICRO.2011.11.025

Belda I, Navascués E, Marquina D et al (2015) Dynamic analysis of physiological properties of Torulaspora delbrueckii in wine fermentations and its incidence on wine quality. Appl Microbiol Biotechnol 99:1911-1922. https://doi.org/10.1007/s0025 3-014-6197-2

Bisson LF, Joseph CML (2009) Yeasts. In: Konig H, Unden G, Frohlich $\mathrm{J}$ (eds) Biology of microorganisms on grapes, in must and in wine. Springer, Berlin

Camarasa C, Sanchez I, Brial P et al (2011) Phenotypic landscape of Saccharomyces cerevisiae during wine fermentation: evidence for origin-dependent metabolic traits. PLoS ONE 6:e25147. https:// doi.org/10.1371/journal.pone.0025147

Capece A, Siesto G, Romaniello R et al (2013) Assessment of competition in wine fermentation among wild Saccharomyces cerevisiae strains isolated from Sangiovese grapes in Tuscany region. LWT Food Sci Technol 54:485-492. https://doi.org/10.1016/j. lwt.2013.07.001

Capece A, Granchi L, Guerrini S et al (2016) Diversity of Saccharomyces cerevisiae strains Isolated from two Italian wine-producing regions. Front Microbiol 7:1018. https://doi.org/10.3389/fmicb .2016 .01018

Ciani M, Fatichenti F (1999) Selective sugar consumption by apiculate yeasts. Lett Appl Microbiol 28:203-206. https://doi.org/10.104 6/j.1365-2672.1999.00505.x

Cioch-Skoneczny M, Satora P, Skotniczny M, Skoneczny S (2018) Quantitative and qualitative composition of yeast microbiota in spontaneously fermented grape musts obtained from cool climate grape varieties Rondo and Regent. FEMS Yeast Res. https://doi. org/10.1093/femsyr/foy089

Cioch-Skoneczny M, Satora P, Skoneczny S, Skotniczny M (2019) Yeasts associated with the spontaneously fermented grape musts 
obtained from cool climate white grape varieties. J Food Nutr Res 58:295-306

Cocolin L, Bisson LF, Mills DA (2000) Direct profiling of the yeast dynamics in wine fermentations. FEMS Microbiol Lett 189:8187. https://doi.org/10.1016/S0378-1097(00)00257-3

Contreras A, Hidalgo C, Henschke PA et al (2014) Evaluation of nonSaccharomyces yeasts for the reduction of alcohol content in wine. Appl Environ Microbiol 80:1670-1678. https://doi.org/10.1128/ AEM.03780-13

de Ponzzes-Gomes CMPBS, de Mélo DLFM, Santana CA et al (2014) Saccharomyces cerevisiae and non-Saccharomyces yeasts in grape varieties of the São Francisco Valley. Braz J Microbiol 45:411416. https://doi.org/10.1590/S1517-83822014000200007

Díaz C, Molina AM, Nähring J, Fischer R (2013) Characterization and dynamic behavior of wild yeast during spontaneous wine fermentation in steel tanks and amphorae. Biomed Res Int 2013:13. https ://doi.org/10.1155/2013/540465

Drumonde-Neves J, Franco-Duarte R, Lima T et al (2016) Yeast biodiversity in vineyard environments is increased by human intervention. PLoS ONE 11:e0160579. https://doi.org/10.1371/journ al.pone.0160579

Gobbi M, Comitini F, Domizio P et al (2013) Lachancea thermotolerans and Saccharomyces cerevisiae in simultaneous and sequential co-fermentation: a strategy to enhance acidity and improve the overall quality of wine. Food Microbiol 33:271-281. https://doi. org/10.1016/j.fm.2012.10.004

Grangeteau C, Roullier-Gall C, Rousseaux S et al (2017) Wine microbiology is driven by vineyard and winery anthropogenic factors. Microb Biotechnol 10:354-370. https://doi. org/10.1111/1751-7915.12428

Hierro N, González Á, Mas A, Guillamón JM (2006) Diversity and evolution of non-Saccharomyces yeast populations during wine fermentation: effect of grape ripeness and cold maceration. FEMS Yeast Res 6:102-111. https://doi.org/10.111 $1 / \mathrm{j} .1567-1364.2005 .00014 . x$

Hornsey IS (2007) The chemistry and biology of winemaking. The Royal Society of Chemistry, Cambridge

Izquierdo Cañas PM, García-Romero E, Heras Manso JM, FernándezGonzález M (2014) Influence of sequential inoculation of Wickerhamomyces anomalus and Saccharomyces cerevisiae in the quality of red wines. Eur Food Res Technol 239:279-286. https ://doi.org/10.1007/s00217-014-2220-1

Jolly NP, Augustyn OPH, Pretorius IS (2006) The role and use of non-Saccharomyces yeasts in wine production. S Afr J Enol Vitic 27:15-38. https://doi.org/10.21548/27-1-1475

Jolly NP, Varela C, Pretorius IS (2014) Not your ordinary yeast: nonSaccharomyces yeasts in wine production uncovered. FEMS Yeast Res 14:215-237. https://doi.org/10.1111/1567-1364.12111

Knight S, Klaere S, Fedrizzi B, Goddard MR (2015) Regional microbial signatures positively correlate with differential wine phenotypes: evidence for a microbial aspect to terroir. Sci Rep 5:14233. https://doi.org/10.1038/srep14233

Lisek J (2011) Winorośl w uprawie przydomowej i towarowej. Hortpress, Dublin

Medina K, Boido E, Dellacassa E, Carrau F (2012) Growth of non-Saccharomyces yeasts affects nutrient availability for
Saccharomyces cerevisiae during wine fermentation. Int J Food Microbiol 157:245-250. https://doi.org/10.1016/J.IJFOODMICR O.2012.05.012

Ocón E, Gutiérrez AR, Garijo P et al (2010) Quantitative and qualitative analysis of non-Saccharomyces yeasts in spontaneous alcoholic fermentations. Eur Food Res Technol 230:885-891. https:// doi.org/10.1007/s00217-010-1233-7

Padilla B, Gil JV, Manzanares P (2016) Past and future of non-Saccharomyces yeasts: from spoilage microorganisms to biotechnological tools for improving wine aroma complexity. Front Microbiol 7:411. https://doi.org/10.3389/fmicb.2016.00411

Ribéreau-Gayon P, Dubourdieu D, Donèche B, Lonvaud A (2006) Handbook of enology: the microbiology of wine and vinifications, 1st edn. Wiley, New York

Romano P, Fiore C, Paraggio M et al (2003) Function of yeast species and strains in wine flavour. Int J Food Microbiol 86:169-180. https://doi.org/10.1016/S0168-1605(03)00290-3

Sabel A, Martens S, Petri A et al (2014) Wickerhamomyces anomalus AS1: a new strain with potential to improve wine aroma. Ann Microbiol 64:483-491. https://doi.org/10.1007/s1321 3-013-0678-x

Sluys SL (2006) Climatic influences on the grapevine: a study of viticulture in the Waipara Basin. University of Canterbury, Thesis

Suárez-Lepe JA, Morata A (2012) New trends in yeast selection for winemaking. Trends Food Sci Technol 23:39-50. https://doi. org/10.1016/J.TIFS.2011.08.005

Swiegers JH, Bartowsky EJ, Henschke PA, Pretorius IS (2005) Yeast and bacterial modulation of wine aroma and flavour. Aust J Grape Wine Res 11:139-173. https://doi.org/10.1111/j.1755-0238.2005. tb00285.x

Van de Water L, Napa V (2009) Monitoring microbes during fermentation. Pract Winer Vineyard J 5:46-50

Van Leeuwen C, Seguin G (2006) The concept of terroir in viticulture. J Wine Res 17:1-10. https://doi.org/10.1080/09571260600633135

Varela C, Borneman AR (2017) Yeasts found in vineyards and wineries. Yeast 34:111-128. https://doi.org/10.1002/yea.3219

Velázquez R, Zamora E, Álvarez ML et al (2015) Effects of new Torulaspora delbrueckii killer yeasts on the must fermentation kinetics and aroma compounds of white table wine. Front Microbiol 6:1-10. https://doi.org/10.3389/fmicb.2015.01222

Walker GM (2011) Pichia anomala: cell physiology and biotechnology relative to other yeasts. Antonie Van Leeuwenhoek 99:25-34. https://doi.org/10.1007/s10482-010-9491-8

Zott K, Miot-Sertier C, Claisse O et al (2008) Dynamics and diversity of non-Saccharomyces yeasts during the early stages in winemaking. Int J Food Microbiol 125:197-203. https://doi.org/10.1016/j. ijfoodmicro.2008.04.001

Publisher's Note Springer Nature remains neutral with regard to jurisdictional claims in published maps and institutional affiliations. 